\title{
EFFECTS OF IONTOPHORETICALLY RELEASED AMINO ACIDS AND AMINES ON PRIMATE SPINOTHALAMIC TRACT CELLS ${ }^{1}$
}

\author{
W. S. WILlCOCKSON, J. M. CHUNG, Y. HORI, K. H. LEE, AND W. D. WILLIS ${ }^{2}$ \\ Marine Biomedical Institute, University of Texas Medical Branch, Galveston, Texas 77550 \\ Received June 10, 1983; Revised September 28, 1983; Accepted September 29, 1983
}

\begin{abstract}
The effects of glutamate (Glu), $\gamma$-aminobutyric acid (GABA), glycine (Gly), serotonin (5-HT), norepinephrine (NE), dopamine (DA), and acetylcholine (ACh) were examined in this study by iontophoretic application onto primate spinothalamic tract (STT) neurons identified antidromically by stimulation in the contralateral thalamus. Drugs were tested for effects on background activity, Glu-induced firing, and activity evoked by pinching of the skin.

Whereas Glu excited STT cells and was thus used for tests of the other compounds, the amino acids GABA and Gly inhibited Glu- and pinch-induced activity in all STT cells examined. STT cells were also inhibited by 5-HT, NE, and DA. Only two cases of excitation by 5-HT were seen (of 58 cells tested). ACh also had inhibitory actions on STT cells, although 3 of 21 cells exhibited some enhancement of activity.

The effects of these compounds on identified STT cells resemble previous demonstrations of the effects of these drugs on dorsal horn interneurons. The results suggest that GABA, Gly, 5-HT, NE, and DA may be inhibitory neurotransmitters on nociceptive STT cells.
\end{abstract}

A key problem to be solved concerning the processing of somatosensory information is the identification of the neurotransmitters that are used in the sensory pathways originating in the periphery, synapsing in the spinal cord and brainstem and projecting to the thalamus and cerebral cortex. Of equal interest are those transmitters that modify transmission along the somatosensory pathways. For example, there may be practical uses of agents that modulate nociceptive transmission in the spinal cord.

Our laboratory has been investigating the responses of spinothalamic tract neurons in the monkey (Willis et al., 1974; Chung et al., 1979). The spinothalamic tract (STT) is a major somatosensory pathway in primates, including humans, and it is crucial for pain sensation (White and Sweet, 1955; Noordenbos and Wall, 1976; Vierck and Luck, 1979). In addition, the STT is likely to contribute to temperature and tactile sensations (White and Sweet, 1955).

Very little is known about the neurotransmitters af-

\footnotetext{
${ }^{1}$ This work was supported by Grants NS 09743 , NS 11255 , and NS 18830 from the National Institutes of Health and by a grant from the Moody Foundation. We wish to thank Helen Willcockson for her expert technical assistance in the surgical preparation of the animals and in the art work. We thank also G. Gonzales for her help with the histology and Phyllis Waldrop for typing the manuscript.

${ }^{2}$ To whom correspondence should be addressed, at Marine Biomedical Institute, 200 University Boulevard, Galveston, TX 77550.
}

fecting the activity of STT cells. We have demonstrated that serotonin $(5-\mathrm{HT})$ released iontophoretically near STT cells usually causes a depression of the background discharges, the responses to noxious stimuli, and glutamate (Glu)-evoked activity (Jordan et al., 1978, 1979). However, some STT cells that have subcutaneous receptive fields can be excited by iontophoretically applied 5HT (Jordan et al., 1979). Recently, it has been shown that primate STT and trigeminothalamic tract cells labeled with retrogradely transported horseradish peroxidase receive synaptic contacts containing enkephalinlike immunoreactivity (Ruda, 1982). Thus, it would be predicted that microiontophoretically applied enkephalin might have a postsynaptic action on primate STT cells.

A number of putative neurotransmitters are present in the spinal cord dorsal horn and have an action on dorsal horn interneurons following microiontophoretic application. These substances include the amino acids glutamic acid, glycine (Gly), and $\gamma$-aminobutyric acid (GABA) (Curtis et al., 1959, 1960; 1968; Graham et al., 1967; Zieglgänsberger and Puil, 1973; McLaughlin et al., 1975 ), the catecholamines norepinephrine (NE) and dopamine (DA) (Engberg and Ryall, 1966; Zivin et al., 1975; Headley et al., 1978), acetylcholine (ACh) (Engberg and Ryall, 1966; Zieglgänsberger and Reiter, 1974; Houser et al., 1983; however, cf., Curtis et al., 1961), and several peptides, including substance $\mathrm{P}$ and somatostatin (Tak- 
ahashi and Otsuka, 1975; Henry, 1976; Hökfelt et al., 1976), in addition to 5-HT and enkephalin.

The present study is a survey of the effects of a number of candidate neurotransmitters released by microiontophoresis in the vicinity of primate STT cells. The experiments are the initial stage of an analysis of the pharmacology of synaptic excitation and inhibition of these neurons that are thought to play an important role in pain mechanisms. The actions of amino acids and amines are described in this paper, and the actions of peptides are described in the companion paper (Willcockson et al., 1984). A preliminary report has been made (Willcockson et al., 1983a).

\section{Materials and Methods}

Experiments were performed on 19 monkeys (Macaca fascicularis) weighing 1.9 to $3.2 \mathrm{~kg}$. Animals were initially anesthetized with a mixture of halothane, nitrous oxide, and oxygen, followed by a single dose of $\alpha$-chloralose (60 $\mathrm{mg} / \mathrm{kg}$, i.v.). Gallamine triethiodide (Flaxedil) was used to immobilize the animal and artificial ventilation was instituted. End-tidal $\mathrm{CO}_{2}$ was maintained between 3.5 and $4.5 \%$. A supplemental infusion of sodium pentobarbital $(5 \mathrm{mg} / \mathrm{kg} / \mathrm{hr})$ and gallamine triethiodide $(4 \mathrm{mg} / \mathrm{kg} /$ $\mathrm{hr}$ ) was given throughout the duration of the experiment. Rectal temperature was regulated near $37^{\circ} \mathrm{C}$.

The lumbosacral spinal cord was exposed by laminectomy at vertebral levels L2 to L6 to allow recordings from STT cells. A craniotomy at the vertex of the skull provided access to the thalamus. In three experiments decorticate spinalized animals were used. Decortication was accomplished by bilateral common carotid artery ligation and spinalization by compression of the cord at the C2 spinal level. No chloralose was given, and supplemental pentobarbital was omitted from the infusion in these animals.

The caudal part of the ventral posterior lateral nucleus of the right contralateral thalamus (VPLc nucleus of Olszewski, 1952) was found by recording potentials evoked by electrical stimulation of the dorsal column and by mechanical stimulation of the hindlimb. The thalamic electrode was then used to activate STT cells antidromically (Trevino et al., 1973). In spinalized animals, lumbar dorsal horn neurons were activated antidromically by surface stimulation of the contralateral lateral column at a high cervical level. The dorsal column was interrupted caudal to this stimulation site to prevent volleys in the dorsal columns from activating STT cells orthodromically (cf. Foreman et al., 1976). STT cells were classified according to their responses to innocuous or noxious mechanical stimuli applied to the receptive field (Chung et al., 1979). In experiments with spinalized animals, antidromically activated dorsal horn cells were classified according to their receptive field characteristics in the same fashion.

Seven-barreled glass microelectrodes were used to apply drugs iontophoretically and to record from STT cells. Extracellular activity was recorded from the center barrel of the array, which contained a low-impedance $(<2$ megohms, measured at $1 \mathrm{kHz}$ ) carbon fiber (Anderson and Cushman, 1981).
Drug concentrations and $\mathrm{pH}$ were as follows: L-monosodium-glutamate salt (Sigma), $0.2 \mathrm{M}, \mathrm{pH} 8.5$; GABA (Sigma), $0.2 \mathrm{M}, \mathrm{pH}$ 3.5; Gly (Sigma), $0.2 \mathrm{M}, \mathrm{pH} 3.5 ; 5-$ HT creatinine sulfate (Sigma), $50 \mathrm{mM}, \mathrm{pH}$ 5.0; L-norepinephrine hydrochloride (NE) (Sigma), $0.1 \mathrm{M}, \mathrm{pH} 4.0$; dopamine hydrochloride (DA) (Sigma), $0.1 \mathrm{M}, \mathrm{pH} 4.0$; acetylcholine iodide (ACh) (Sigma), $1.0 \mathrm{M}, \mathrm{pH}$ 5.0. All drugs were dissolved in sterile, deionized water $\left(\mathrm{dH}_{2} \mathrm{O}\right)$, except NE and DA which were made up in $5 \times 10^{-5} \mathrm{M}$ ascorbic acid in $\mathrm{dH}_{2} \mathrm{O}$ to prevent oxidation. Glu and 5$\mathrm{H}^{\prime} \mathrm{T}$ were dissolved 4 to $5 \mathrm{hr}$ before use; all other drugs were made up immediately before filling the electrodes. With the exception of Glu, all compounds were applied with cationic current. Retaining currents were always less than $7 \mathrm{nA}$. Current neutralization was used during all drug applications through a balancing barrel filled with $0.2 \mathrm{M} \mathrm{NaCl}$.

Drugs were tested on STT neurons for effects on background activity, Glu-induced firing, and activity evoked by innocuous (brush) and noxious (pinch with a small clip) mechanical stimuli. Glu activation was achieved by pulsed release of Glu ions ( 5 to $25 \mathrm{nA}$ ) for 5 sec at 10 -sec intervals. Drugs were iontophoresed continuously over a 40 -sec period.

Extracellular spikes were used to trigger a window discriminator. Peristimulus time histograms were compiled by computer. Control responses to background, Glu, or mechanically evoked activity were compared to responses during the test drug application. Percentage of inhibition or excitation was calculated as [number of impulses during test period/number of impulses during control period) $\times 100 \%]-100 \%$.

At the conclusion of each experiment stimulating and recording sites were marked by passing direct current through the electrodes. Steel electrode marks in the thalamus were enhanced histologically by the Prussian blue reaction. Carbon-fiber marks at STT cell locations were visible as microlesions.

\section{Results}

The locations of marks where STT cells were recorded are shown in Figure 1. Because most of the cells were tested with both amines and peptides, the recording spots from all experiments described in this and the following paper (Willcockson et al., 1984) are condensed into one figure. Not every recording site was marked, often because several cells were in close proximity to each other. Most of the recordings were made in laminae I and V, where STT cells projecting to the VPLc nucleus are most concentrated (Willis et al., 1974).

A total of 48 STT cells in 16 different animals were tested with biogenic amines. Cell depths ranged from 400 to $2070 \mu \mathrm{m}$, and antidromic thresholds were 20 to 600 $\mu \mathrm{A}$. Antidromic latencies ranged from 2.6 to $13 \mathrm{msec}$, corresponding to conduction velocities of 12 to $60 \mathrm{~m} / \mathrm{sec}$ and characteristic of myelinated axons. Typing of cells according to their responses to innocuous or noxious stimuli applied to their receptive fields was according to the following scheme (Chung et al., 1979): low threshold (LT) cells responded to innocuous but not additionally to noxious mechanical stimulation of the skin; wide dynamic range (WDR) cells responded to innocuous 


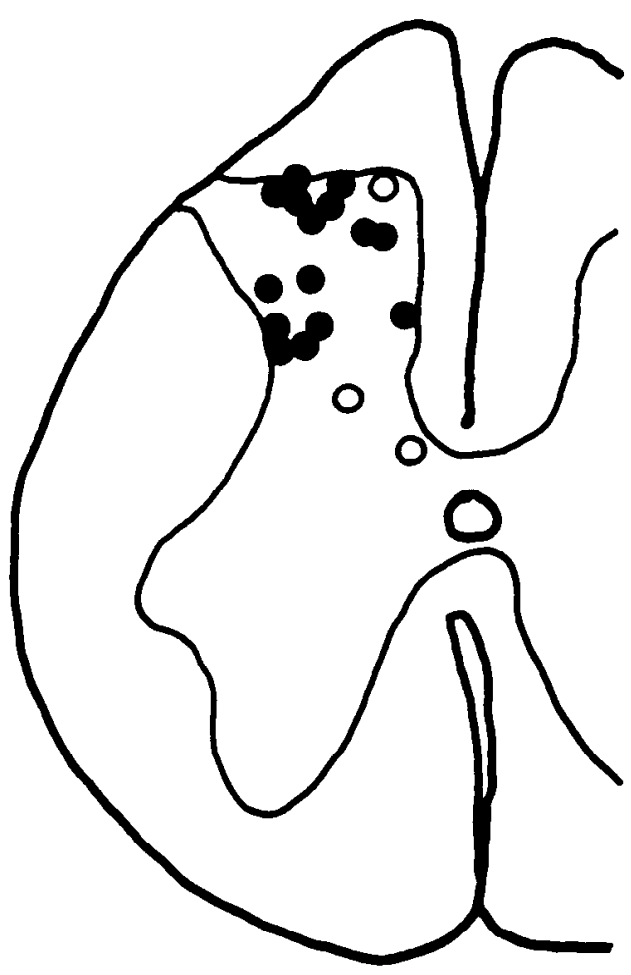

Figure 1. Histologic localization of neurons recorded from the lumbar spinal cord. Not all recording sites in the cord were marked because tested cells were often located close to one another. This figure includes marks of three STT-like cells which were recorded in spinalized animals (open circles). Most cells were examined for effects of both biogenic amines and peptides. Therefore, this figure summarizes cell locations for both this and the following paper (Willcockson et al., 1984).

stimuli but were even more responsive to noxious stimuli; high threshold (HT) cells could be activated only by noxious stimuli; "deep" (D) STT cells were excited chiefly or exclusively by stimulation of subcutaneous tissues. The distribution of STT cells in the present sample was as follows: LT cells, 1; WDR cells, 38; HT cells, 7; D cells, 1 . The remaining cell could not be classified.

In addition to the cells described above, a total of 12 cells were examined in the three experiments in unanesthetized, decorticate spinalized animals. Therefore, by definition, these cells cannot accurately be termed STT cells. Of the cells tested in spinalized animals with biogenic amines, 2 were classified as LT, 9 as WDR, and 1 as HT. Depths for these cells ranged from 800 to 2000 $\mu \mathrm{m}$, antidromic latencies were from 2.8 to $7.8 \mathrm{msec}$, and thresholds were from $200 \mu \mathrm{A}$ to $1 \mathrm{~mA}$.

It should be stated at the outset that none of the drugs tested in this and the following paper (Willcockson et al., 1984) had obvious differential effects on STT cells located at various depths within the dorsal horn nor on STT cells of different classifications. Furthermore, there were no obvious differences in the effects of the amines on cells in the two different animal preparations.

Glu was tested on every cell. With several cells, two to four tracks were necessary following initial detection of the antidromic spike of the cell before the microelectrode array was close enough to the cell that an excitatory response to Glu could be elicited at the current strengths used. In all of the experiments, we noticed only five cells that could not be excited with Glu. These cells were not studied further, and they were not counted in the total. Forty-eight STT cells and the 12 STT-like cells observed in spinalized animals were excited by iontophoretic application of Glu. The thresholds for excitation ranged from 2 to $20 \mathrm{nA}$. A current response relationship for the excitation of an STT cell by Glu is shown in Figure $2 B$. The single-pass peristimulus time histogram shows the burst discharges produced when Glu was pulsed iontophoretically for 5 sec every $10 \mathrm{sec}$, with an increment in current intensity after every fourth pulse.

The inhibitory and/or excitatory actions of several amino acids and amines were tested primarily by their actions on the responses of STT cells to Glu pulses. In some cases, these agents were also or instead tested against background discharges or against the responses to stimulation of the receptive field. As a control of possible interactions between iontophoretic currents and the responses to Glu ions, we examined the effects of current passed through a barrel filled with saline. Figure 2, $C$ and $D$, shows that anodal currents of 100 and 150 nA had no effect on the responses of an STT cell to Glu pulses.

GABA and Gly were strongly inhibitory on all six STT cells examined. Thresholds were always $\leq 10 \mathrm{nA}$. Both GABA and Gly reduced Glu-induced activity (in six cells each) and the response to pinch (in three cells each). Figure $3, A$ and $B$, illustrates the GABA- and Gly-induced reductions of responses to pulsed Glu. Inhibition of activity produced by noxious pinch by these agents is seen in Figure $3, C$ and $D$.

5-HT had an inhibitory action on STT cells and similar cells in spinalized animals. 5 - $\mathrm{HT}$ was tested in all 58 cells against the activity induced by the pulsed release of Glu for $5 \mathrm{sec}$ at 10 -sec intervals. Figures $4 B$ and $5 C$ demonstrate the reduction of Glu-induced bursts of activity by 5 -HT applied continuously for 40 -sec periods. Ninety percent of the 58 cells tested with $5-\mathrm{HT}$ were inhibited. In four cells no 5 -HT effect was observed. Only one cell was found which had a clear excitatory response to iontophoretically applied 5-HT. This cell was classified as HT. In one other cell three different results were found, depending upon the dose of 5-HT applied. No effect was observed at $50 \mathrm{nA}$, inhibition occurred at 100 $\mathrm{nA}$, and excitation was seen at $>150 \mathrm{nA}$ of $5-\mathrm{HT}$. The position of this cell in relation to the electrode tip changed, however, during the recording period, as shown by changes in the Glu response; thus the apparent excitation may have been artifactual. Thresholds for $5-\mathrm{HT}$ effects most frequently occurred around 50 to $100 \mathrm{nA}$, although extremes of $10 \mathrm{nA}$ and $200 \mathrm{nA}$ were seen.

5 -HT was also tested against the background activity of five cells; all five were inhibited. Testing of $5-\mathrm{HT}$ on responses to mechanical stimuli of the ipsilateral hindlimb showed inhibition of brush-induced activity in 2 of 2 cells and inhibition of activity due to pinching with a small clip in 9 of 13 cells; in 4 cells there was no effect of 5 -HT on evoked activity. Three cells were examined for 5-HT's effects on discharges evoked by sural nerve 

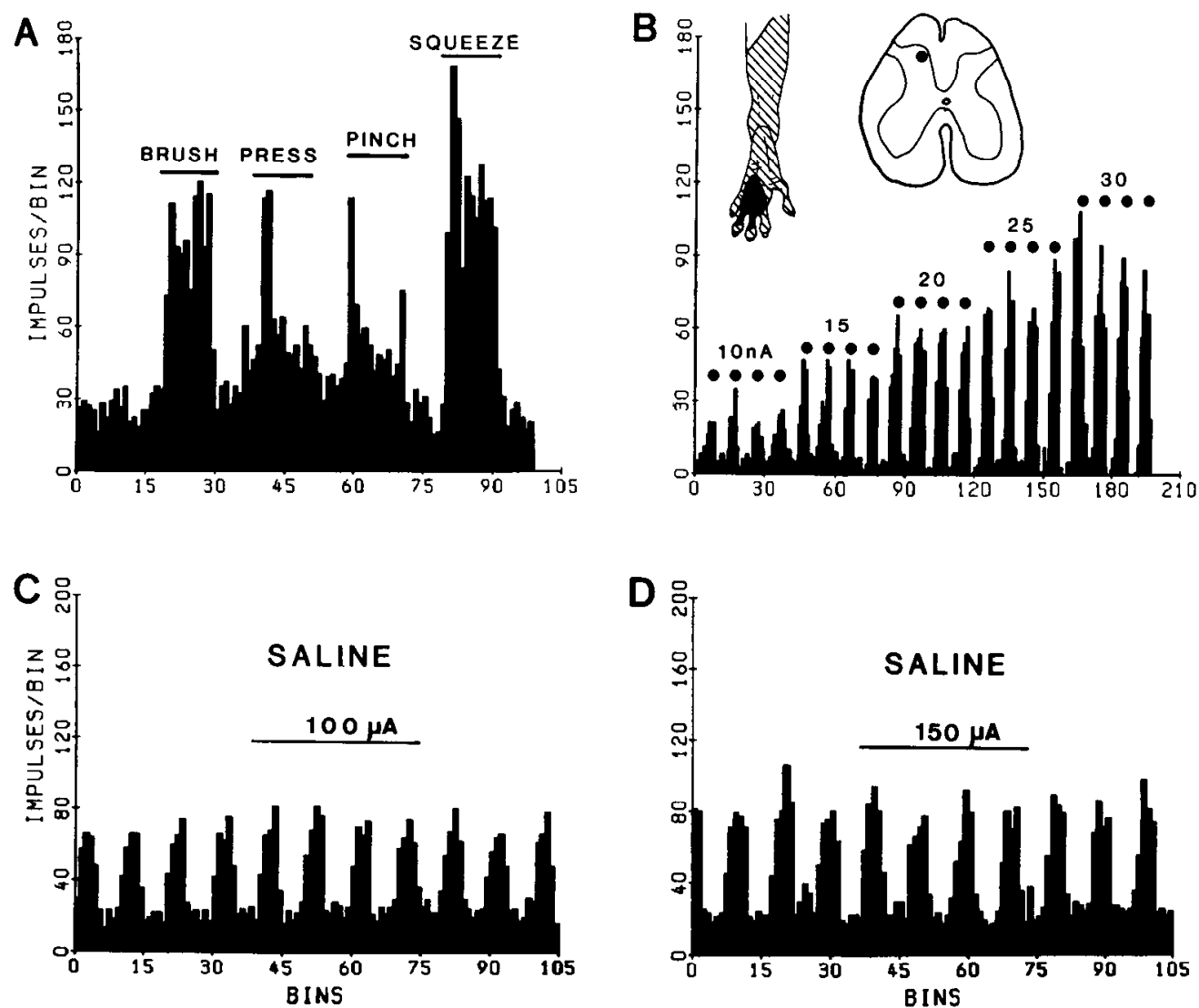

Figure 2. Responses of STT cells to different doses of Glu and lack of effect of iontophoretic current. $A$, Responses of the cell to graded intensities of mechanical stimuli applied to the ipsilateral foot are shown in a single-pass peristimulus time histogram as impulses per bin (1-sec bins). Stimulation was maintained during the periods indicated by the bars. $B$, Insets show receptive field and STT cell location. The histogram illustrates dose response data for Glu activation of this STT cell. Glu was pulsed for $5 \mathrm{sec}$ at 10 -sec intervals. A different current strength was applied every $40 \mathrm{sec}$. Trials at a given strength are indicated by each set of four dots. Bin width $=1$ sec. $C$ and $D$, Lack of effect of cationic iontophoretic currents of 100 and $150 \mathrm{nA}$ on responses of an STT cell to Glu pulses ( $20 \mathrm{nA}$ in $C$ and $25 \mathrm{nA}$ in $D$ ). The responses of the same cell to Glu pulses were inhibited by ACh and $5-\mathrm{HT}$ at $150 \mathrm{nA}$ (not illustrated).
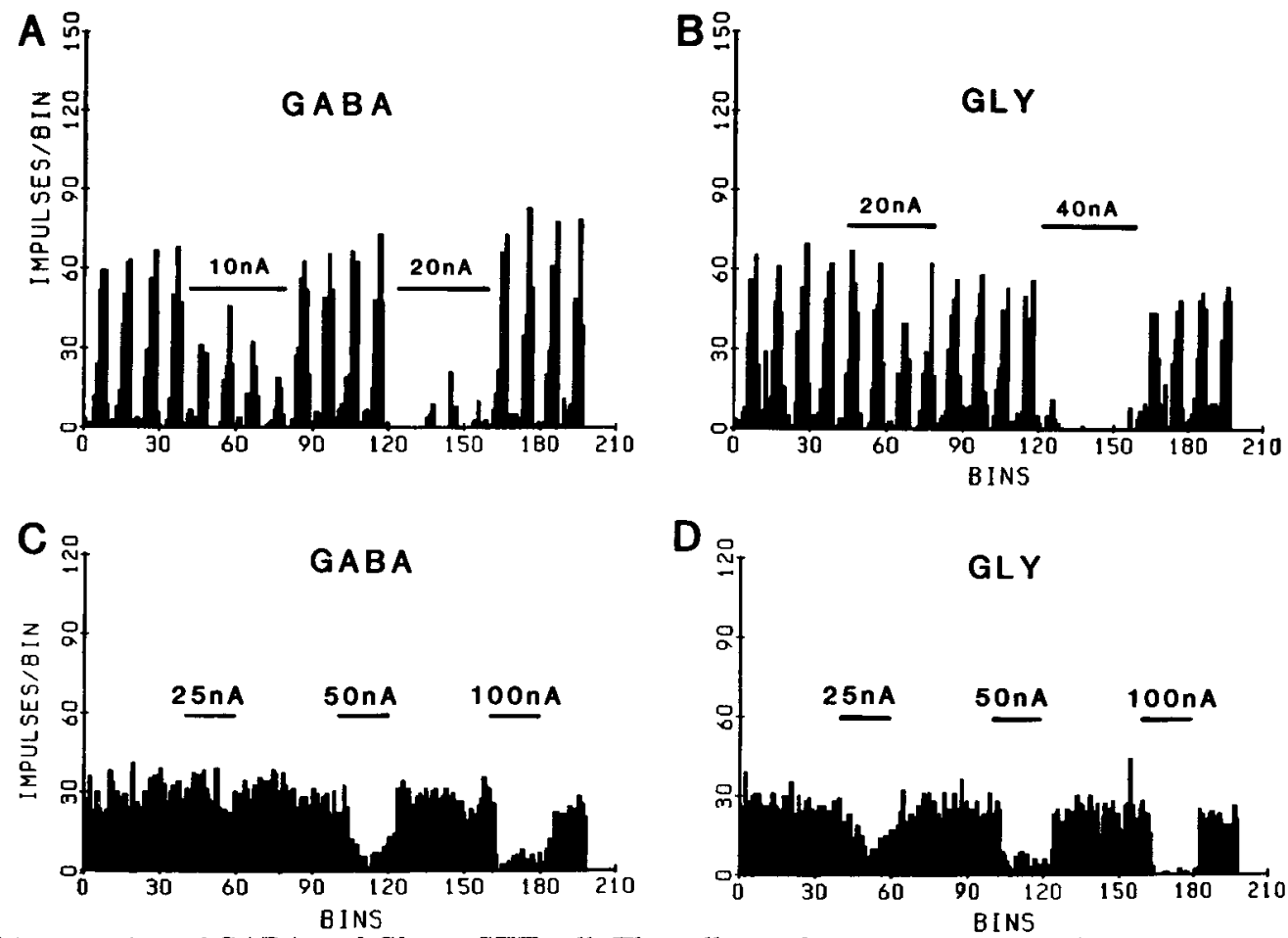

Figure 3. Inhibitory action of GABA and Gly on STT cell. The cell was the same as that used for Figure $2, A$ and $B$. $A$ and $B$, The single-pass peristimulus time histograms demonstrate the effects of GABA and Gly, respectively, on the bursts of activity elicited by pulsed release of Glu for 5 sec at 10 -sec intervals. Bin width $=1$ sec. GABA or Gly was applied during the periods indicated by the bars at the doses indicated. $C$ and $D$, GABA and Gly inhibition of activity elicited by noxious pinching of the ipsilateral foot. Pinch was continued throughout the recording period. The location of this cell was not marked because of its close proximity to the cell seen in $A$ and $B$. Bin width $=1$ sec. 
stimulation. The background (prestimulus) activity, responses to $A$ fiber volleys and responses to $C$ fiber volleys were all reduced by 5 -HT in all three cells. The greatest decreases were seen in the background activity and $\mathrm{C}$ fiber-evoked responses.

NE inhibited all STT cells (and STT-like cells in spinalized animals) tested. Inhibition of Glu-induced activity was seen in all 12 cells examined ( 6 of which were in spinalized preparations). NE also inhibited the responses to brushing in two of two cells and to pinching in three of five cells. NE had no effect on the responses to pinch in the remaining two cells. Thresholds for inhibition ranged from 25 to $100 \mathrm{nA}$. Examples of NE's effect on Glu and pinch-evoked activity in an STT cell are illustrated in Figures $5 D$ and $6, C$ and $D$.

DA was also an inhibitory substance when tested on STT cells. In 15 of 17 cells (88\%), 3 of which were in spinalized preparations, the response to Glu was reduced. DA inhibition of Glu-induced activity is seen in Figure $4 C$. In one cell no effect was seen, and in another, DA excited at $10 \mathrm{nA}$ but inhibited at $25 \mathrm{nA}$. DA was tested against a noxious pinch in six cells. In three cells the response to pinch was inhibited and in the three others no effect of DA was observed. The thresholds for inhibition ranged from 10 to $150 \mathrm{nA}$.

ACh was applied to 21 STT cells. Inhibition of Gluinduced firing occurred in 13 cells $(62 \%)$. In five cells ACh had no obvious effect on the Glu response. In three cells $\mathrm{ACh}$ appeared to enhance the response to Glu, although in two of the three this facilitation was small (10 to 20\%). Four of the STT cells demonstrating inhibition by ACh showed an apparent enhancement of the Glu response (10 to $30 \%$ ) after ACh current was stopped.

Figure $4 D$ shows the inhibitory effect of $\mathrm{ACh}$ on pulsed Glu activity in an STT cell and a later elevation of activity after ACh current was terminated. The excitatory effect did not appear to be dose related and hence this phenomenon could be explained by movement of the cell relative to the electrode. When ACh was tested against pinch, inhibition was observed in two of five cells and no effect was seen in the remaining three cells. ACh effects were first observable at 25 to $150 \mathrm{nA}$.

The effects of all of the biogenic amines examined are summarized in Table I. Only amine effects on Glu- or pinch-induced activity are included since most cells were tested only in these ways.

\section{Discussion}

The results of this study indicate that a variety of putative neurotransmitters have a predominantly inhibitory action on primate STT cells. The only consistently excitatory substance examined in the present work was Glu, although an excitatory action of substance $\mathrm{P}$ on STT cells will be described in the following paper (Willcockson et al., 1984). The fact that Glu ions excite STT cells has already been demonstrated by Jordan et al.
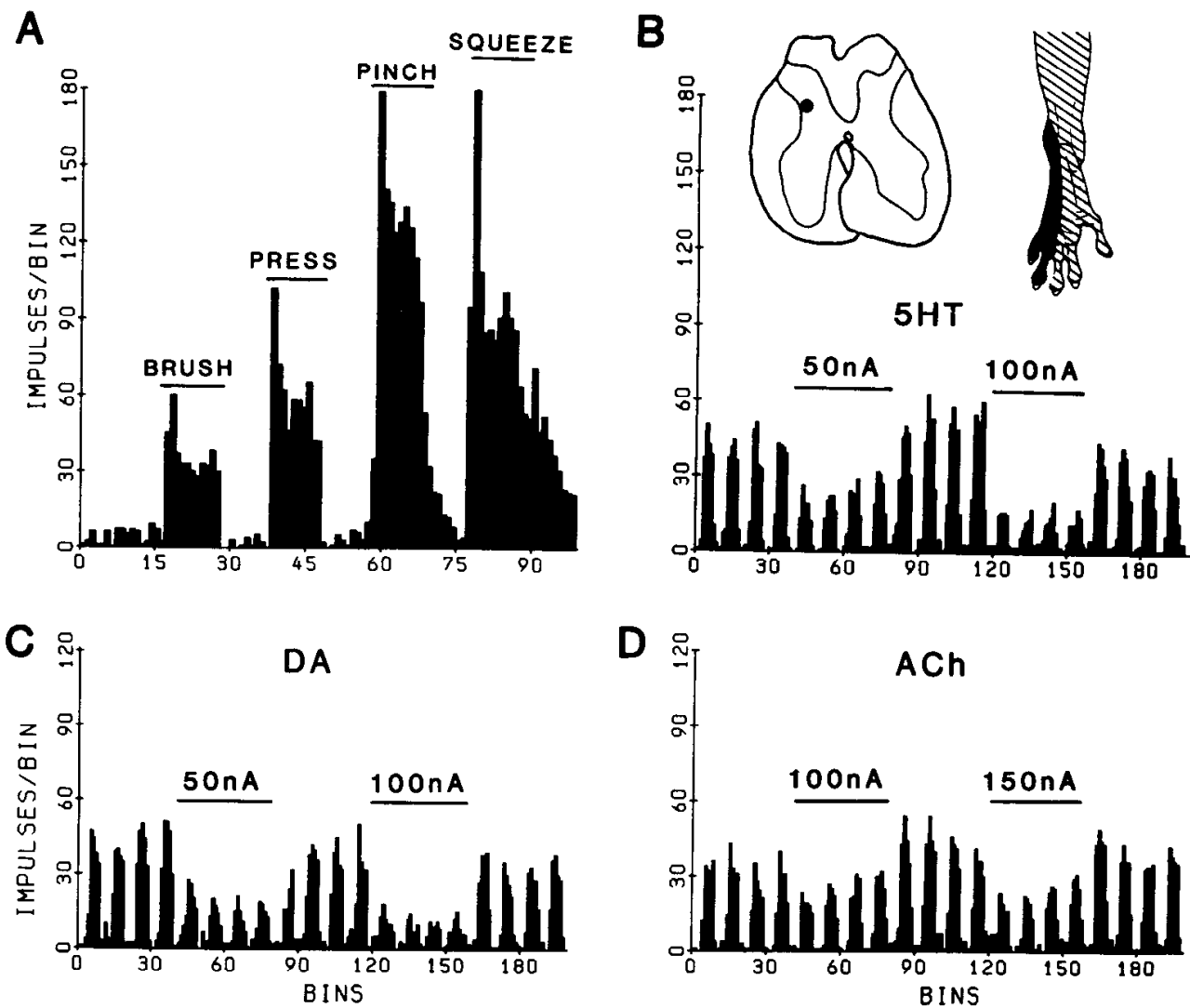

Figure 4. Drug effects on an STT cell. $A$, Responses of the cell to innocuous and noxious mechanical stimuli applied to the ipsilateral foot. $B$, Insets show STT cell location and receptive field. The single-pass peristimulus time histogram below demonstrates the effect of 5 -HT on Glu-induced activity. Bin width $=1$ sec. $C$ and $D$, Effects of DA and ACh, respectively, on pulsed Glu excitation of the cell. 
A
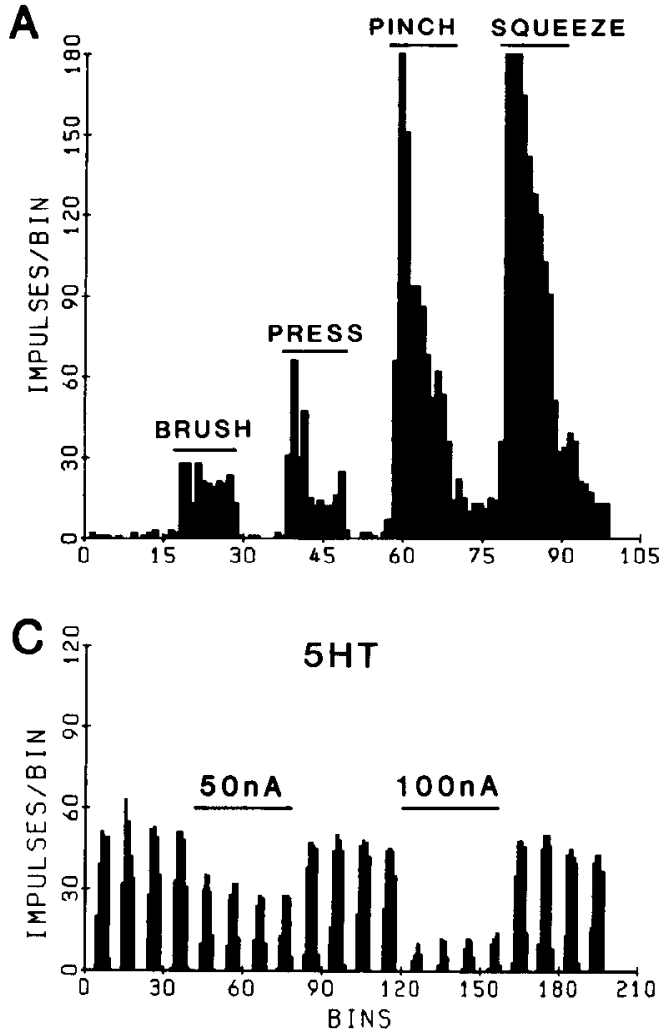

B
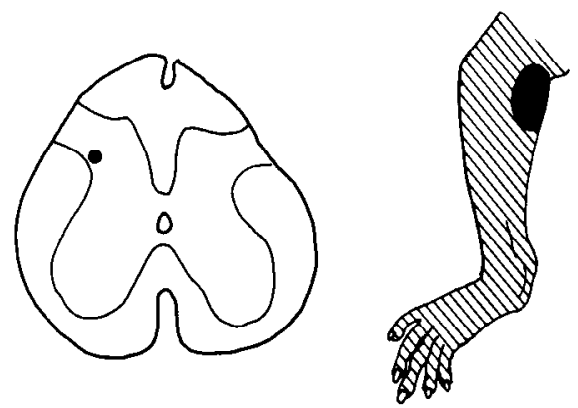

NE

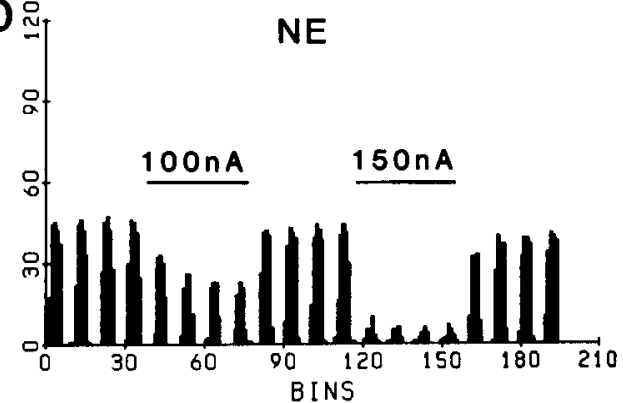

Figure 5. Effects of 5-HT and NE on an STT cell. A, Responses of the cell to graded mechanical stimuli. $B$, STT cell location and receptive field. $C$ and $D$, Single-pass peristimulus time histograms showing current-related inhibition of Glu responses by 5 -HT and NE, respectively. Bin width $=1$ sec.

A
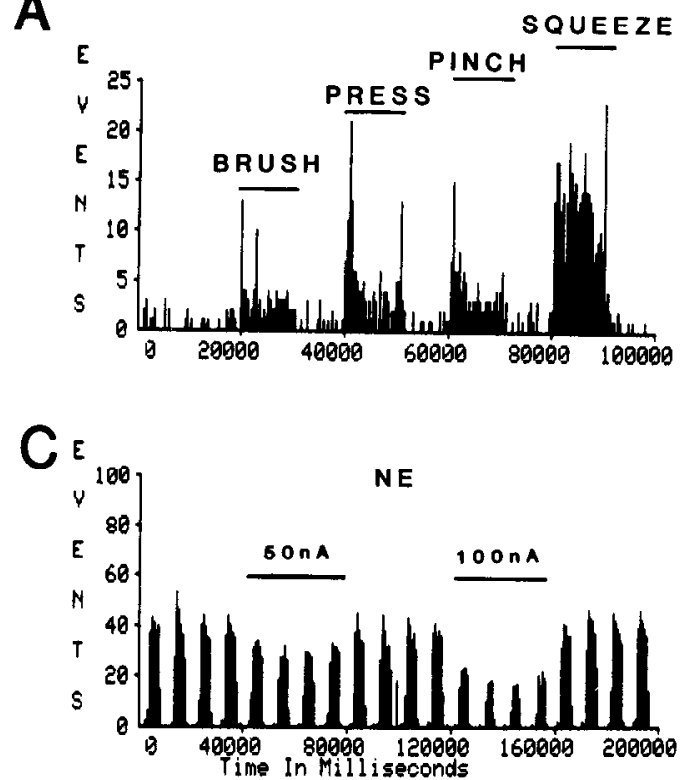
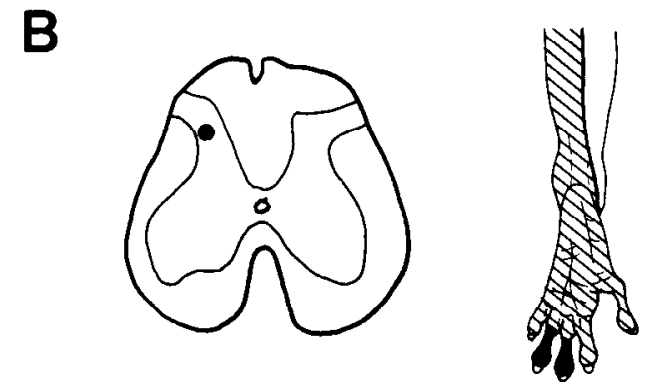

D

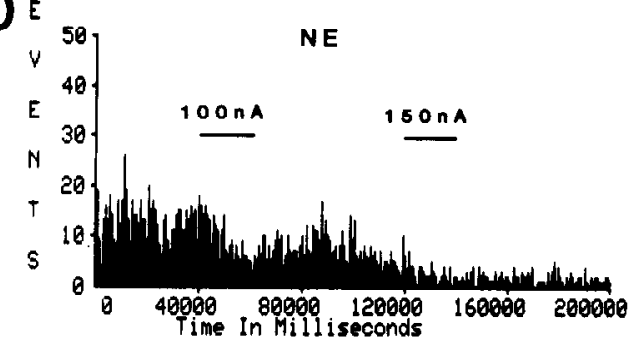

Figure 6. Effect of NE on Glu-induced and pinch-induced firing of an STT cell. A, Activity induced by application of four strengths of mechanical stimulation to the receptive field on the ipsilateral hindlimb. The single-pass peristimulus time histogram in this figure plots excitatory events against the time in milliseconds. Bin width $=400$ msec. $B$, STT cell location and receptive field. $C$, Current-related inhibition of the responses to pulsed release of Glu. $D, \mathrm{NE}$ effects on activity induced by application of a small clip (pinch) to the receptive field. The activity following application of $150 \mathrm{nA}$ of NE was strongly reduced but did recover to $60 \%$ of control approximately $2 \mathrm{~min}$ after the last event (at $200 \mathrm{sec}$ ) recorded in this histogram. Bin width $=800 \mathrm{msec}$ for $C$ and $D$. 
TABLE I

Biogenic amine effects on STT and STT-like cells ${ }^{a}$

\begin{tabular}{lllllll}
\hline Drug $^{b}$ & Excitation $^{*}$ & Inhibition $^{\text {e }}$ & $\begin{array}{c}\text { No } \\
\text { Effect }\end{array}$ & $\begin{array}{c}\text { Multiple } \\
\text { Effects }^{d}\end{array}$ & Total & $\begin{array}{c}\text { Thresholds } \\
\text { (nA) }\end{array}$ \\
\hline \multicolumn{7}{c}{ A. vs. Glu Excitation } \\
GABA & 0 & $6(100 \%)$ & 0 & 0 & 6 & $<10$ \\
Gly & 0 & $6(100 \%)$ & 0 & 0 & 6 & $\leq 10$ \\
5-HT & $1(57 \%)$ & $52(96 \%)$ & 4 & 1 & 58 & $10-200$ \\
NE & 0 & $12(95 \%)$ & 0 & 0 & 12 & $25-100$ \\
DA & 0 & $15(76 \%)$ & 1 & 1 & 17 & $10-150$ \\
ACh & $3(30 \%)$ & $13(66 \%)$ & 5 & 0 & 21 & $25-150$ \\
GABA & 0 & $3(100 \%)$ & 0 & 0 & 3 & $10-25$ \\
Gly & 0 & $3(100 \%)$ & 0 & 0 & 3 & $10-25$ \\
5-HT & 0 & $9(71 \%)$ & 4 & 0 & 13 & $25-100$ \\
NE & 0 & $3(80 \%)$ & 2 & 0 & 5 & $25-100$ \\
DA & 0 & $3(45 \%)$ & 3 & 0 & 6 & $25-50$ \\
ACh & 0 & $2(30 \%)$ & 3 & 0 & 5 & $50-150$ \\
\hline
\end{tabular}

${ }^{a}$ These data include drug effects on both STT cells and STT-like dorsal horn cells in spinalized animals. See the text for further breakdown of the results.

${ }^{b}$ Barrel concentrations for GABA and Gly $=0.2 \mathrm{M}$, for $5-\mathrm{HT}=0.05$ $\mathrm{M}$, for $\mathrm{NE}$ and $\mathrm{DA}=0.1 \mathrm{M}$, and for $\mathrm{ACh}=1.0 \mathrm{M}$.

${ }^{c}$ The number of cells responding as indicated by heading. In parentheses, the maximum percentage of excitation (column 2) or inhibition (column 3) seen with currents $\leq 150 \mathrm{nA}$.

${ }^{d}$ Different effects on a single cell due to varying dosage or position. See the text for further clarification.

$(1978,1979)$. Glu has an excitatory action on a variety of spinal cord neurons, including dorsal horn interneurons (Curtis et al., 1960). There are difficulties in proving that Glu is a true neurotransmitter, but it seems likely that it is one (Curtis, 1979; Watkins and Evans, 1981).

The putative inhibitory amino acid transmitters, Gly and GABA, were found to be strong inhibitors of STT cells. These substances have been shown to inhibit dorsal horn interneurons in previous studies (Curtis et al., 1959, 1968). GABA is believed to play a role in presynaptic inhibition, in addition to its action as a postsynaptic inhibitory transmitter (Eccles et al., 1963; McLaughlin et al., 1975; Curtis et al., 1977). In our experiments, emphasis was placed on the ability of various inhibitory substances to reduce the responses of STT cells to Gluevoked excitation. A reduction in Glu responses is thought to indicate a postsynaptic action of the inhibitory substance, although other interpretations are possible (Puil, 1981). Thus, we believe that GABA, as well as glycine, may have an action on postsynaptic receptors on STT cells, with a resultant inhibitory action. It is possible that STT cells in lamina I are contacted synaptically by GABAergic stalked cells (Hunt et al., 1981). However, the inhibition we observed of the responses of STT cells to noxious stimuli could have been due to a postsynaptic or a presynaptic action or both.

The inhibition of STT cells by 5 -HT confirms the results of Jordan et al. $(1978,1979)$. With respect to an excitatory action on some STT cells, we found only two cells that showed any evidence of excitation in the present study; however, only one "deep" STT cell was found in the present sample, and this was the type of STT cell found most likely to be excited by $5-\mathrm{HT}$ by Jordan et al.
(1979). The predominantly inhibitory action of 5-HT on nociceptive STT cells is consistent with a number of previous observations that have led to the hypothesis that 5 -HT is one of the neurotransmitters in the "intrinsic analgesia systems" (see review by Willis, 1982). For example, 5 -HT has been shown by several groups to inhibit nociceptive dorsal horn interneurons after iontophoretic release either in the vicinity of the interneurons or into the substantia gelatinosa (Randic and $\mathrm{Yu}$, 1976; Belcher et al., 1978; Headley et al., 1978; Griersmith and Duggan, 1980). Stimulation in the nucleus raphe magnus or in the periaqueductal gray matter produces inhibition of nociceptive dorsal horn interneurons by a pathway that appears to include a serotonergic component (Guilbaud et al., 1973; Carstens et al., 1981a; Rivot et al., 1980, 1982; Yezierski et al., 1982b). The descending pathway presumably involves serotonergic raphe-spinal neurons (Bowker et al., 1981), although the possibility of a serotonergic synaptic linkage in the brainstem should not be discounted (Yezierski et al., 1982a). There are still discrepancies (cf. Belcher et al., 1978; Griersmith et al., 1981; Yezierski et al., 1982b), but the weight of the evidence favors the hypothesis that serotonergic axons descend from the brainstem raphe, and terminate on and inhibit nociceptive dorsal horn interneurons, including STT cells. However, an additional presynaptic effect (as in the case of GABA) is also possible (Carstens et al., 1981b; Proudfit et al., 1980).

The catecholamines, NE and DA, were also inhibitory when applied iontophoretically onto STT cells. Others have shown that iontophoretically applied NE reduces the background activity, amino acid-evoked activity, and the responses to noxious stimuli of dorsal horn interneurons (Engberg and Ryall, 1966; Belcher et al., 1978; Headley et al., 1978). NE rarely excites spinal cord interneurons. As in the case of 5-HT, there is evidence for a role of catecholamines in the "intrinsic analgesia systems" (reviewed by Willis, 1982). Descending catecholaminergic pathways to the spinal cord appear to include noradrenergic projections from the nucleus locus ceruleus and subceruleus and the dorsolateral pontine tegmentum (Nygren and Olson, 1977; Westlund et al., 1983), an epinephrine-containing projection from the medulla (Ross et al., 1981), and a putative dopaminergic pathway from the hypothalamus (Blessing and Chalmers, 1979). As in the case of 5-HT, there is evidence for a catecholamine action on the analgesia pathways in the brainstem, as well as in the spinal cord (Hammond et al., 1980). Thus, systemic administration of drugs affecting monoamine synapses can have complex effects, with the possibility of reciprocal and even cancelling actions at brainstem and spinal cord levels.

ACh generally had an inhibitory action in the present experiments, although there was sometimes a delayed excitatory action. It is possible that the excitation was an artifact of movement of the microelectrode array with respect to the neurons under study. A similar facilitation following a depression was seen by Engberg and Ryall (1966) when they applied ACh iontophoretically to dorsal horn interneurons. They suggested that the mechanism was a reduced densensitization of the excitatory amino 
acid used to evoke responses by the interneurons. Others have shown variable effects of ACh released iontophoretically near dorsal horn interneurons (Curtis et al., 1961; Engberg and Ryall, 1966). Iontophoretically applied ACh has been described to increase the afterdischarges of dorsal horn interneurons to noxious heat stimuli and to potentiate the responses to stimulation of the $\mathrm{C}$ fibers in the sural nerve (Sastry, 1979). There is evidence for a cholinergic component of the "intrinsic analgesia systems" (see Willis, 1982). However, it is not clear whether the cholinergic synapse is at the spinal cord level or in the brainstem (Behbehani, 1982; Willcockson et al., $1983 b)$.

If all of the substances we have shown to have an action on STT cells function as true neurotransmitters and participate in a variety of control systems impinging on STT cells, it is evident that the mechanisms available for modulating nociceptive transmission are rich and varied. The following paper will provide evidence for further complexity by showing the actions of several peptides on STT cells (Willcockson et al., 1984).

\section{References}

Anderson, C. W., and M. R. Cushman (1981) A simple and rapid method for making carbon fiber microelectrodes. J. Neurosci. Methods 4: 435-436.

Behbehani, M. M. (1982) The role of acetylcholine in the function of the nucleus raphe magnus and in the interaction of this nucleus with the periaqueductal gray. Brain Res. 252: 299-307.

Belcher, G., R. W. Ryall, and R. Schaffner (1978) The differential effects of 5-hydroxytryptamine, noradrenaline and raphe stimulation on nociceptive and non-nociceptive dorsal horn interneurones in the cat. Brain Res. 151: 307-321.

Blessing, W. W., and J. P. Chalmers (1979) Direct projection of catecholamine (presumably dopamine)-containing neurons from hypothalamus to spinal cord. Neurosci. Lett. 11: $35-40$.

Bowker, R. M., K. N. Westlund, and J. D. Coulter (1981) Origins of serotonergic projections to the spinal cord in rat: An immunocytochemical-retrograde transport study. Brain Res. 226: 187-199.

Carstens, E., M. Fraunhoffer, and M. Zimmermann (1981a) Serotonergic mediation of descending inhibition from midbrain periaqueductal gray, but not reticular formation, of spinal nociceptive transmission in the cat. Pain 10:149-167.

Carstens, E., D. Klumpp, M. Randić, and M. Zimmermann (1981b) Effect of iontophoretically applied 5-hydroxytryptamine on the excitability of single primary afferent $\mathrm{C}$ - and A-fibers in the cat spinal cord. Brain Res. 220: 151-158.

Chung, J. M., D. R. Kenshalo, Jr., K. D. Gerhart, and W. D. Willis (1979) Excitation of primate spinothalamic neurons by cutaneous C-fiber volleys. J. Neurophysiol. 42: 1354-1369.

Curtis, D. R. (1979) Problems in the evaluation of glutamate as a central nervous system transmitter. In Glutamic Acid: Advances in Biochemistry and Physiology, L. J. Filer, S. Garattini, M. R. Kare, and W. A. Reynolds, eds., pp. 163175, Raven Press, New York.

Curtis, D. R., J. W. Phillis, and J. C. Watkins (1959) The depression of spinal neurones by $\gamma$-amino- $N$-butyric acid and $\beta$-alanine. J. Physiol. (Lond.) 146: 185-203.

Curtis, D. R., J. W. Phillis, and J. C. Watkins (1960) The chemical excitation of spinal neurones by certain acidic amino acids. J. Physiol. (Lond.) 150: 656-682.

Curtis, D. R., J. W. Phillis, and J. C. Watkins (1961) Cholin- ergic and non-cholinergic transmission in the mammalian spinal cord. J. Physiol. (Lond.) 158: 296-323.

Curtis, D. R., L. Hösli, and G. A. R. Johnston (1968) A pharmacological study of the depression of spinal neurones by glycine and related amino acids. Exp. Brain Res. 6: 1-18.

Curtis, D. R., D. Lodge, and S. J. Brand (1977) GABA and spinal afferent terminal excitability in the cat. Brain Res. 130: 360-363.

Eccles, J. C., R. Schmidt, and W. D. Willis (1963) Pharmacological studies on presynaptic inhibition. J. Physiol. (Lond.) 168: $500-530$.

Engberg, I., and R. W. Ryall (1966) The inhibitory action of noradrenaline and other monoamines on spinal neurones. J. Physiol. 185: 298-322.

Foreman, R. D., J. E. Beall, A. E. Applebaum, J. D. Coulter, and W. D. Willis (1976) Effects of dorsal column stimulation on primate spinothalamic tract neurons. J. Neurophysiol. 39: 534-546.

Graham, L. T., R. P. Shank, R. Werman, and M. H. Aprison (1967) Distribution of some synaptic transmitter suspects in cat spinal cord: Glutamic acid, aspartic acid, $\gamma$-aminobutyric acid, glycine and glutamine. J. Neurochem. 14: 465-472.

Griersmith, B. T., and A. W. Duggan (1980) Prolonged depression of spinal transmission of nociceptive information by 5 HT administered in the substantia gelatinosa: Antagonism by methysergide. Brain Res. 187: 231-236.

Griersmith, B. 'I', A. W. Duggan, and R. A. North (1981) Methysergide and supraspinal inhibition of the spinal transmission of nociceptive information in the anesthetized cat. Brain Res. 204: 147-158.

Guilbaud, G., J. M. Besson, J. L. Oliveras, and J. C. Liebeskind (1973) Suppression by LSD of the inhibitory effect exerted by dorsal raphe stimulation on certain spinal cord interneurons in the cat. Brain Res. 61: 417-422.

Hammond, D. L., R. A. Levy, and H. K. Proudfit (1980) Hypoalgesia induced by microinjection of a norepinephrine antagonist in the raphe magnus: Reversal by intrathecal administration of a serotonin antagonist. Brain Res. 201: $475-479$.

Headley, P. M., A. W. Duggan, and B. T. Griersmith (1978) Selective reduction by noradrenaline and 5-hydroxytryptamine of nociceptive responses of cat dorsal horn neurones. Brain Res. 145: 185-189.

Henry, J. L. (1976) Effects of substance $\mathbf{P}$ on functionally identified units in cat spinal cord. Brain Res. 114: 439-451.

Hökfelt, T., R. Elde, O. Johansson, R. Luft, G. Nilsson, and A. Arimura (1976) Immunohistochemical evidence for separate populations of somatostatin-containing and substance $P$ containing primary afferent neurons in the rat. Neuroscience 1: $131-136$.

Houser, C. R., G. D. Crawford, R. P. Barber, P. M. Salvaterra, and J. E. Vaughn (1983) Organization and morphological characteristics of cholinergic neurons: An immunocytochemical study with a monoclonal antibody to choline acetyltransferase. Brain Res. 266: 97-119.

Hunt, S. P., J. S. Kelly, P. C. Emson, J. R. Kimmel, R. J. Miller, and J. Y. Wu (1981) An immunohistochemical study of neuronal populations containing neuropeptides or $\gamma$-aminobutyrate within the superficial layers of the rat dorsal horn. Neuroscience 6: 1883-1898.

Jordan, L. M., D. R. Kenshalo, Jr., R. F. Martin, L. H. Haber, and W. D. Willis (1978) Depression of primate spinothalamic tract neurons by iontophoretic application of 5-hydroxytryptamine. Pain 5: 135-142.

Jordan, L. M., D. R. Kenshalo, Jr., R. F. Martin, L. H. Haber, and W. D. Willis (1979) Two populations of spinothalamic tract neurons with opposite responses to 5-hydroxytryptamine. Brain Res. 164: 342-346. 
McLaughlin, B. J., R. Barber, K. Saito, E. Roberts, and J. Y. $\mathrm{Wu}$ (1975) Immunocytochemical localization of glutamate decarboxylase in rat spinal cord. J. Comp. Neurol. 164: 305322.

Noordenbos, W., and P. D. Wall (1976) Diverse sensory functions with an almost totally divided spinal cord. $\Lambda$ case of spinal cord transection with preservation of part of one anterolateral quadrant. Pain 2: 185-195.

Nygren, L. G., and L. Olson (1977) A new major projection from locus coeruleus: The main source of noradrenergic nerve terminals in the ventral and dorsal columns of the spinal cord. Brain Res. 132: 85-93.

Olszewski, J. (1952) The Thalamus of Macaca Mulatta, Karger, New York.

Proudfit, H. K., A. A. Larson, and E. G. Anderson (1980) The role of GABA and serotonin in the mediation of raphe-evoked spinal cord dorsal root potentials. Brain Res. 195: 149-165.

Puil, E. (1981) S-Glutamate: Its interactions with spinal neurons. Brain Res. 3: 229-322.

Randić, M., and H. H. Yu (1976) Effects of 5-hydroxytryptamine and bradykinin on cat dorsal horn neurones activated by noxious stimuli. Brain Res. 111: 197-203.

Rivot, J. P., A. Chaouch, and J. M. Besson (1980) Nucleus raphe magnus modulation of response of rat dorsal horn neurons to unmyelinated fiber inputs: Partial involvement of serotonergic pathways. J. Neurophysiol. 44: 1039-1057.

Rivot, J. P., C. Y. Chiang, and J. M. Besson (1982) Increase of serotonin metabolism within the dorsal horn of the spinal cord during nucleus raphe magnus stimulation, as revealed by in vivo electrochemical detection. Brain Res. 238: 117126.

Ross, C. A., D. M. Armstrong, D. A. Ruggiero, V. M. Pickel, T. H. Joh, and D. J. Reis (1981) Adrenaline neurons in the rostral ventrolateral medulla innervate thoracic spinal cord: A combined immunocytochemical and retrograde transport demonstration. Neurosci. Lett. 25: 257-262.

Ruda, M. A. (1982) Opiates and pain pathways: Demonstration of enkephalin synapses on dorsal horn projection neurons. Science 215: 1523-1525.

Sastry, B. R. (1979) Substance P effects on spinal nociceptive neurons. Life Sci. 24: 2169-2178.

Takahashi, T., and M. Otsuka (1975) Regional distribution of substance $P$ in the spinal cord and nerve roots of the cat and the effect of dorsal root section. Brain Res. 87: 111.

Trevino, D. L., J. D. Coulter, and W. D. Willis (1973) Location of cells of origin of spinothalamic tract in lumbar enlargement of the monkey. J. Neurophysiol. 36: 750-761.
Vierck, C. J., and M. M. Luck (1979) Loss and recovery of reactivity to noxious stimuli in monkeys with primary spinothalamic cordotomies, followed by secondary and tertiary lesions of other cord sectors. Brain 102: 233-248.

Watkins, J. C., and R. H. Evans (1981) Excitatory amino acid transmitters. Annu. Rev. Pharmacol. Toxicol. 21: 165-204.

Westlund, K. N., R. M. Bowker, M. G. Ziegler, and J. D. Coulter (1983) Noradrenergic projections to the spinal cord of the rat. Brain Res. 263: 15-31.

White, J. C., and W. H. Sweet (1955) Pain, Its Mechanisms and Neurosurgical Control, Charles C Thomas, Springfield, IL.

Willcockson, W. S., J. M. Chung, Y. Hori, K. H. Lee, and W. D. Willis (1983a) Iontophoretic study of biogenic amine and peptide effects on spinothalamic tract cells. Soc. Neurosci. Abstr. 9: 1.

Willcockson, W. S., K. D. Gerhart, C. L. Cargill, and W. D. Willis (1983b) Effects of biogenic amines on raphe-spinal tract cells. J. Pharmacol. Exp. Ther. 225: 637-645.

Willcockson, W. S., J. M. Chung, Y. Hori, K. H. Lee, and W. D. Willis (1984) Effects of iontophoretically released peptides on primate spinothalamic tract cells. J. Neurosci. 4: 741-750.

Willis, W. D. (1982) Control of nociceptive transmission in the spinal cord. In Progress in Sensory Physiology, Ed. 3, D. Ottoson, ed., pp. 1-159, Springer-Verlag, Berlin.

Willis, W. D., D. L. Trevino, J. D. Coulter, and R. A. Maunz (1974) Responses of primate spinothalamic tract neurons to natural stimulation of hindlimb. J. Neurophysiol. 37: 358372.

Yezierski, R. P., R. M. Bowker, G. A. Kevetter, K. N. Westlund, J. D. Coulter, and W. D. Willis (1982a) Serotonergic projections to the caudal brain stem: A double label study using horseradish peroxidase and serotonin immunocytochemistry. Brain Res. 239: 258-264.

Yezierski, R. P., T. K. Wilcox, and W. D. Willis (1982b) The effects of serotonin antagonists on the inhibition of primate spinothalamic tract cells produced by stimulation in nucleus raphe magnus or periaqueductal gray. J. Pharmacol. Exp. Ther. 220: 266-277.

Zieglgänsberger, W., and E. Puil (1973) Actions of glutamic acid on spinal neurones. Exp. Brain Res. 17: 35-49.

Zieglgänsberger, W., and C. Reiter (1974) A cholinergic mechanism in the spinal cord of cats. Neuropharmacology 13:519527.

Zivin, J. A., J. L. Reid, J. M. Saavedra, and I. J. Kopin (1975) Quantitative localization of biogenic amines in the spinal cord. Brain Res. 99: 293-301. 